Excellency in Council will await with interest the reports showing the results of the special measures which have been adopted in some provinces. It is clear that much still remains to be done ; but if sustained efforts are made and well-considered plans adopted for the extermination of wild beasts and deadly snakes, His Excellency in Council believes that the number of deaths from these causes will in course of time be materially reduced.Simla, November 8, I882."

From the above it appears that more vigorous measures than any hitherto adopted have been taken for the destruction of venomous snakes, and the contrast of the results of $\mathrm{I} 88 \mathrm{I}$ with those of $\mathrm{I} 880$, warrant the anticipation of further benefit if these measures are only carried out with a sustained determination to succeed. It is mainly a question of perseverance and the expenditure of money, and one can hardly imagine a more desirable object on which to expend both energy and rupees. But it is essential that the system be laid down on some general principles for the whole of India, to be worked out in detail, according to the needs or peculiarities of each district. There should, in short, be a department with a responsible chief and subordinate agents, for whom certain rules should be laid down to be carried out steadily and without hindrance throughout the country, leaving much of the detail to the discretion of local authorities. I would insist on the importance of carrying it out on broad principles everywhere. When such a department is constituted under a proper head-and there are many persons well fitted for such a duty-then, I believe, venomous snakes and other noxious animals will decrease in numbers, and people will cease to be startled by these appalling losses of life.

J. FAYRER

\section{SIR F. WHITWORTH'S MECHANICAL PAPERS ${ }^{1}$}

THE fact that, by an order in Council of August 26, I88 $\mathrm{I}$, some 300 Whitworth gauges of various dimensions have been adopted as standards by the Board of Trade, is so important a recognition of the value of the labours of $\operatorname{Sir} \mathrm{J}$. Whitworth in improving mechanical measurement, that the occasion has been selected for republishing certain papers which have been long well known among engineers, but which have not hitherto been accessible to the public generally.

The first paper in the series is on plane metallic surfaces, and the proper mode of preparing them, and contains an account of an invention of great simplicity, but of the highest practical importance. Such plates, when worked up to an extreme degree of accuracy and finish, form an approximation to a plane surface which would surprise and delight any geometrician who had an opportunity of critically examining and testing their qualities. They consist of an assemblage of minute bright surfaces very evenly distributed over a plate of cast iron, and very near together.

As to their qualities, there is not space here to describe them, but they have formed the subject-matter of an excellent lecture by Prof. Tyndall, at an evening meeting of the Royal Institution in the year 1875 .

Passing from these so-called true planes, we refer to a step involving an original conception which has led to the construction of the new standard gauges. The production of an approximately true plane surface gave an increased value and importance to the feeling of contact between prepared metallic surfaces, and resulted in the invention of a measuring machine which was made to depend on the sense of touch instead of upon optical contrivances, and was founded entirely on truth of surface.

x "Papers on Mechanical Subjects." By Sir Joseph Whitworth, Bart., F.R.S., D.C.L, Vol. I. True Planes, Screw Threads, and Standard Measures. (London: Spon.)
The improvement consisted in the substitution of end for line measure, and inasmuch as these are technical terms, it may be well to explain them.

As stated in the last paper of the series, the English standard yard is an example of line measure, being represented by the interval between two lines drawn across two gold studs sunk in a bronze bar about 38 inches long, the temperature being at $62^{\circ}$ Fabrenheit.

The standard yard, from the subdivisions of which the standard inch has been obtained on the Whitworth system, is a rectangular metal bar with plane sides capable of resting along its whole length in rectangular $V$ grooves, which are plane surfaces, while the ends of the bar are planes lying perpendicular to its axis. The bar is exactly 36 inches long, and the measurement is complete when the degree of contact between its ends and two small true planes abutting against them is ascertained. Such a measurement is, of course, end measure, and its accuracy depends throughout upon truth of surface, and also upon truth of position of surface. The ends of the bar must be perpendicular to its axis, and the planes which feel those ends must be truly parallel to each other, and one at least must be movable to and fro without deviating at all from the position of parallelism to its fixed neighbour,

Then comes the question of the amount of shifting or the movable plane. That is done by a micrometer screw, the linear motion for one graduation of the micrometer head, which can be easily read without a lens, being in some cases I-ro,ooth of an inch, and in other cases I- $I, \infty 00,000$ th of an inch.

There is not space to discuss the measuring machine, whether as capable of producing cylindrical gauges varying by I-IO,oooth of an inch, or as capable of reproducing a standard inch or a standard yard to a degree of accuracy which leaves the microscope far behind in the contest.

It must suffice to point out that the reprinted papers are full of interest, as showing the manner in which Sir J. Whitworth has thought out and accomplished the work of improving the construction of machinery, and it is matter of regret that those who are occupied in teaching mechanics have not better opportunities than now exist of becoming practically conversant with the subject-matter of the collected papers.

\section{NOTES}

From Punta Arenas, near the extremity of South America, intelligence has been received that the fourth section of the German expedition sent out to observe the transit of Venus has been particularly successful, Professor Auvers having managed to take exceedingly good photographs and numerous measurements.

A Telegram received from Monte Video states that the Volage has anchored in these roads from Santa Cruz in Patagonia. Capt. Fleuriais and observers of the transit of Venus were on board, returning to France with their instruments, photographs, and other documents.

M. TRÉPled, in a communication to the Paris Academy on his observation of the transit in Algiers, states that clouds rendered the ordinary observations of little value, but that some good results were obtained with the spectroscope on the borders of the planet in the region from $\mathrm{A}$ to $\mathrm{E}$; while some photographs were obtained in the green, the blue, and the violet. The examination of the spectral lines in the groups $A, B, \alpha$, in the regions comprised between $\alpha, D, E$, did not show, M. Trépied states, anything which could be attributed to a selective absorption produced by an atmosphere on the planet. The same inference is deduced from the photographs. 